\title{
Concurrent nephrotic syndrome and acute renal failure caused by chronic lymphocytic leukemia $(C L L)$ : a case report and literature review
}

\author{
Xianrui Dou', Haitang Hu', Yongle Ju', Yongdong Liu², Kaifu Kang ${ }^{1}$, Shufeng Zhou ${ }^{3}$ and Wenfang Chen ${ }^{2 *}$
}

\begin{abstract}
Kidney injury associated with lymphocytic leukemia (CLL) is typically caused by direct tumor infiltration which occasionally results in acute renal failure. Glomerular involvement presenting as proteinuria or even nephrotic syndrome is exceptionally rare. Here we report a case of 54-year-old male CLL patient with nephrotic syndrome and renal failure. The lymph node biopsy confirmed that the patients had CLL with remarkable immunoglobulin light chain amyloid deposition. The renal biopsy demonstrated the concurrence of AL amyloidosis and neoplastic infiltration. Combined treatment of fludarabine, cyclophosphamide and rituximab resulted in remission of CLL, as well as the renal disfunction and nephrotic syndrome, without recurrence during a 12-month follow-up. To our knowledge, this is the first case of CLL patient showing the nephrotic syndrome and acute renal failure caused by AL amyloidosis and neoplastic infiltration. Though AL amyloidosis caused by plasma cell dyscrasia usually responses poorly to chemotherapy, this patient exhibited a satisfactory clinical outcome due to successful inhibition of the production of amylodogenic light chains by combined chemotherapy.
\end{abstract}

Virtual Slides: The virtual slide(s) for this article can be found here: http://www.diagnosticpathology.diagnomx.eu/ vs/2479639195566762.

\section{Background}

$\mathrm{AL}$ amyloidosis is characterized by widespread, progressive deposition of amyloid fibrils derived from monoclonal immunoglobulin (Ig) light chains, leading to multi-system organ failure among which the kidneys and heart are most frequently affected [1]. Although AL amyloidosis is typically caused by plasma cell proliferative disease especially multiple myeloma, it can also be caused by other lymphoproliferative disorders of B-cells such as lymphoplasmacytic lymphoma, of which the neoplastic B cells produce monoclonal immunoglobulin light chains [2]. Only few cases of AL amyloidosis associated with chronic lymphocytic leukemia (CLL) have been reported [2-5]. Another relatively common injury caused CLL is the direct neoplastic cell infiltration as demonstrated by autopsy studies [6], but acute renal failure due to severe infiltration is rare [7-9].

\footnotetext{
* Correspondence: chwfang@mail.sysu.edu.cn

${ }^{2}$ Department of Pathology, the First Affiliated Hospital of Sun Yat-sen

University, $58^{\#}$ Zhongshan Road II, Guangzhou 510080, China

Full list of author information is available at the end of the article
}

In this report, we present a patient with nephrotic syndrome and renal failure associated with CLL. The patient completely recovered from the nephrotic syndrome and renal dysfunction after CLL was controlled with chemotherapy. We have reviewed the literature and discussed the relationship between CLL and amyloidosis and the pathological implications.

\section{Case presentation \\ Clinic data}

A 54-year-old male Chinese patient was admitted to the Shunde People's hospital on March 7, 2008, complaining of nocturia and edema of face and both lower extremities for more than two months. The patient had no history of any renal disease. Physical examinations revealed normal vital signs, moderate hypertension $(162 / 96 \mathrm{mmHg})$ and pitting edema of the lower extremities. Enlargement of lymph nodes involving inguinal, axillary, submaxillary and supraclavicular fossa with a diameter of more than $1 \mathrm{~cm}$ was found. The remainder of the examination was unremarkable. 
Both his hemoglobin and erythrocyte count were in normal range. The leukocytes increased to $16.8 \times 10^{9} / \mathrm{L}$ with elevated lymphocytic proportion by $61.8 \%$ (normal range: $24 \%-40 \%)$. Urine analysis showed proteinuria of $5 \mathrm{~g} / \mathrm{L}$ with a RBC count of $150 / \mu \mathrm{L}$. His 24 -hour total urinary protein excretion was $5.11 \mathrm{~g}$ and serum albumin level was $38 \mathrm{~g} / \mathrm{L}$. The blood creatinine $(\mathrm{Cr})$ concentration was $290.04 \mu \mathrm{mol} / \mathrm{L}$ (normal range: $53-115 \mathrm{umol} / \mathrm{l}$ ) and the urea nitrogen (BUN) was $13.49 \mathrm{mmol} / \mathrm{L}$ (normal range: $2.9-8.6 \mathrm{mmol} / \mathrm{l}$ ) indicating the impaired renal function. Both Ig-M (kappa) monoclonal protein and free kappa were detected in his serum by immunofixation electrophoresis, but urine Bence Jones protein was negative. He also had high serum IgM concentration $(3.9 \mathrm{~g} / \mathrm{L}$, normal range: $0.50-2.20 \mathrm{~g} / \mathrm{L})$ while the IgG and IgA levels were normal. The serum complement 3 decreased to $0.03 \mathrm{~g} / \mathrm{L}$ (normal range: $0.79-1.17 \mathrm{~g} / \mathrm{l}$ ). The tests for antinuclear antibody, rheumatoid factor, cryoglobulin and hepatitis virus $B$ and $C$ all showed negative. The bone marrow aspiration showed increased cellularity and the accumulation of small immature-appearing lymphocytes, without increase of plasma cells. Flow cytometric analysis showed that those lymphocytes were positive for CD5, CD19, CD20, HLA-DR, kappa and surface membrane IgM, and negative for CD3, CD7, CD10, CD38 and lambda (Figure 1). The CT scanning revealed numerous intumesced lymph nodes in the neck, thoracic cavity, celiac and retroperitoneal space (Figure 2). Liver and spleen were both enlarged with dense and fine sonogram. The echocardiography indicated mildly and symmetrically thickened left ventricular wall. The patient was diagnosed with acute renal failure together with a nephrotic-range proteinuria.

\section{Pathological findings}

The biopsy from one of enlarged lymph nodes showed effacement of the architecture with a dark background of cells consisting of numerous small lymphocyte-like cells with scattered larger cells including prolymphocytes and paraimmunoblasts. The predominant cells were slightly larger than normal lymphocytes (Figure 3A) with round nucleolus and clumped chromatin. Only mild nuclear irregularity was noted. The mitotic phase was occasionally observed. Immunohistochemistry showed these cells were positive for CD20, CD79 $\alpha$, CD5 (Figure 3B), and CD23 but negative for CD3, CD45RO, CyclinD1, CD38, and CD138. An important finding was that there were patches of homogeneous hyaline material in the interstitium and vascular walls (Figure 3A), which was verified to be amyloid protein by Congon-red staining (Figure 3C). Immunoassay confirmed that the deposit was positive for kappa but negative for lambda and serum amyloid A protein (Figure 3D-E). The patient was diagnosed as CLL with systemic AL amyloidosis.

Because of unknown reason of worsening of proteinuria and decreasing of the Alb down to $29 \mathrm{~g} / \mathrm{l}$ after 2 courses of combinative chemotherapy including $2 \mathrm{mg}$ chlorambucil and $30 \mathrm{mg}$ prednisone, a kidney biopsy was performed. The patient's renal tissue submitted for light microscopy consisted of two cores of renal cortex and medulla containing 35 glomeruli. There was no global or segmental sclerosis. All glomeruli showed diffused, eosinophilic and homogeneous material in mesangial area replacing the normal mesangial matrix (Figure 4A). Some extended into the peripheral capillary walls and appeared as large subendothelial deposits or even seemed to be located in the capillary lumen. The deposits were amyloid as shown by strong Congo-red positive staining (Figure 4B) and bright apple green birefringence under polarized light (Figure 4C). The same deposits were found in the interstitium, peritubular space and blood vessel walls. Immunohistochemistry showed that the amyloid was kappa positive but negative for lambda and serum amyloid A protein. Only mild focal tubular atrophy was found. Clusters of lymphocyte-like cells which were CD5 and CD20 positive infiltrated in renal interstitium, occupying less than $30 \%$ of the area of the cortical tissue examined (Figure 4D and 4E).
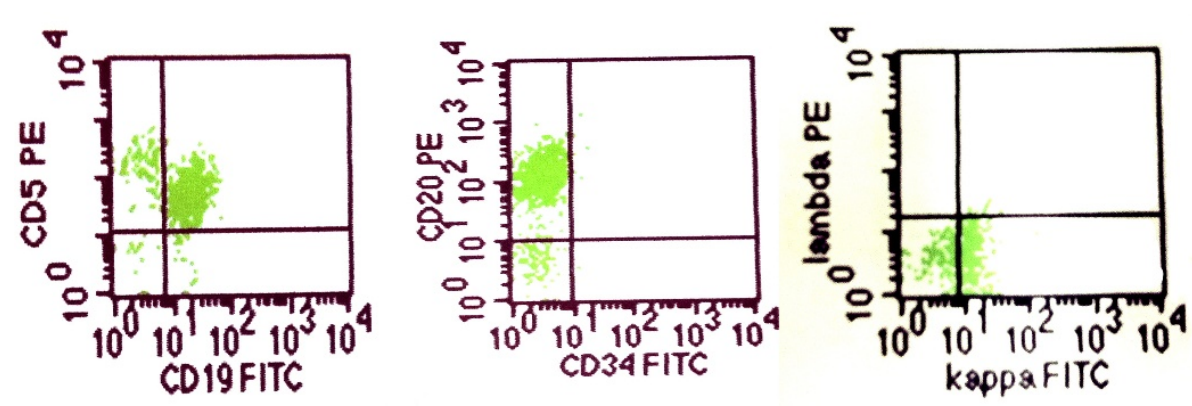

Figure 1 Flow cytometric analysis of the bone marrow aspiration. The proliferated lymphocytes were positive for CD5, CD20, CD19 and kappa light chain. 

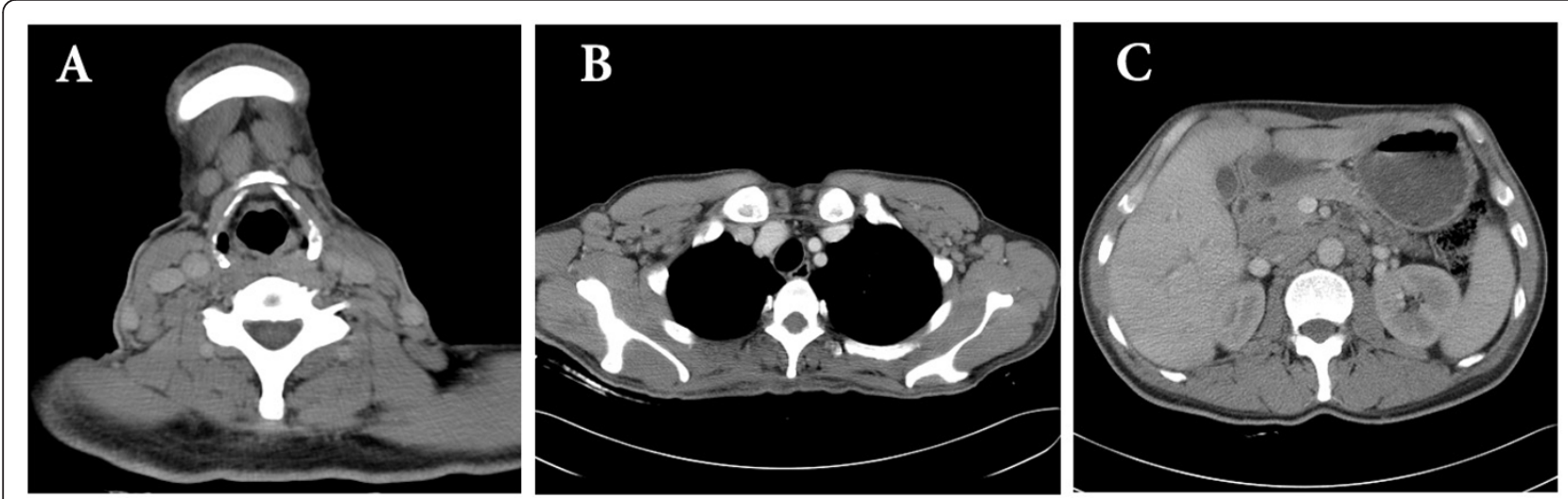

Figure 2 Computed tomography scanning of the neck, chest and abdomen (A). Enlargement of numerous lymph nodes in the neck. (B). Numerous enlarged lymph nodes in axillary space. (C) Enlargement and confluence of lymph nodes in the peritoneal cavity.

The small arteries exhibited mild fibrointimal thickening and the arterioles appeared segmental hyalinosis. Immunofluorescence staining showed faint staining of IgG and IgM along the peripheral capillary in glomeruli while IgA, C3, C1q and fibrinogen were negative. Non-branched fibrils with $10 \mathrm{~nm}$-diameters were detected in mesangium and subendothelial area (Figure 4F) by electronic microscopy. All these histological changes indicated a direct infiltration of the tumor cells in the renal parenchyma together with AL amyloidosis.

\section{Treatment and following-up}

Chemotherapy was given by combination of $44 \mathrm{mg}$ fludarabine and $20 \mathrm{mg}$ dexamethasone from July 24, 2008 to September 26, 2008 for 3 courses of treatment. After that, the lymph nodes size decreased and the edema was dramatically ameliorated with decreased serum $\mathrm{Cr}$ $(200 \mu \mathrm{mol} / \mathrm{L})$, increased serum albumin $(39.96 \mathrm{~g} / \mathrm{L})$, declined serum IgM level $(2.38 \mathrm{~g} / \mathrm{L})$ and slightly reduced 24-hour urinary protein excretion (4.22 g/24 h). However, the patient developed a severe bone marrow depression defined by markedly reduced blood cell count (erythrocytes: $1.66 \times 10^{12} / \mathrm{L}$, leukocytes: $0.62 \times 10^{9} / \mathrm{L}$, platelet: $\left.21 \times 10^{9} / \mathrm{L}\right)$. Then the chemotherapy regimen was adjusted (fludarabine $50 \mathrm{mg}$, CTX $0.3 \mathrm{~g}$ and rituximab $600 \mathrm{mg}$ ). After 3 courses of treatment from Nov 27, 2008 to Feb 19, 2009, the patient achieved a satisfactory hematologic response. His serum IgM concentration gradually decreased to the normal level and the monoclonal immunoglobulin was undetectable by serum immunofixation electrophoresis. At the same time, the patient experienced a gradual improvement in clinical status and decrease in the proteinuria and serum creatine. His renal function, urinary protein and serum C3 level were recovered entirely in Sept 2009 (24-hour urinary protein excretion: $139.20 \mathrm{mg} / 24 \mathrm{~h}$, urine routine test: negative, serum $\mathrm{Cr}$ : $121.00 \mu \mathrm{mol} / \mathrm{L}$, serum C3 level $0.96 \mathrm{~g} / \mathrm{L})$.

\section{Discussion}

Proteinuria caused by direct infiltration of neoplastic cells is generally mild. Severe proteinuria or even nephrotic syndrome often suggests glomerular involvement $[7,10]$. Though CLL is rarely complicated with nephrotic syndrome, a spectrum of glomerular diseases including light chain deposition disease (LCDD), AL, membranoproliferative glomerulonephritis (MPGN) [11], membrane nephropathy $(\mathrm{MN})$ and minimal change disease (MCD) have been reported, which suggests the presence of various pathogenesis pathways of CLLassociated nephrotic syndrome[2,7,11-13]. The glomerular injuries may be directly caused by the lymphoplasmacytic neoplasm through a paraprotein deposition process which finally results in amyloidosis or monoclonal immunoglobulin deposition disease or the indirect immune-mediated mechanisms may also be involved. In our case, the monoclonal Ig light chain detected in the sera was the same class as that found on the surface membrane of lymphocytes and the amyloid in the kidney and lymph node, indicating that the monoclonal Ig originated from the proliferating cells. Based on this finding as well as the histopathological observations, we made a diagnosis of CLL associated AL amyloidosis. The reason that we could not detect monoclonal Ig light chain in the lymphocytic cells by immunohistochemistry may be ascribed to the inaccessibility of epitope after tissue fixation.

Histologically, the leukaemic infiltratation in the kidney can be nodular or interstitial in CLL. In this patient, both patterns were observed. When the infiltration is nodular, especially when there are clusters of cells around sclerotic glomeruli or atrophic tubules, it is important to determine whether it is tumor infiltration leading to their destruction or is only local inflammation secondary to glomerular scelerosis and tubular atrophy caused by other glomerulopathies. The mixture of various inflammatory cells generally 

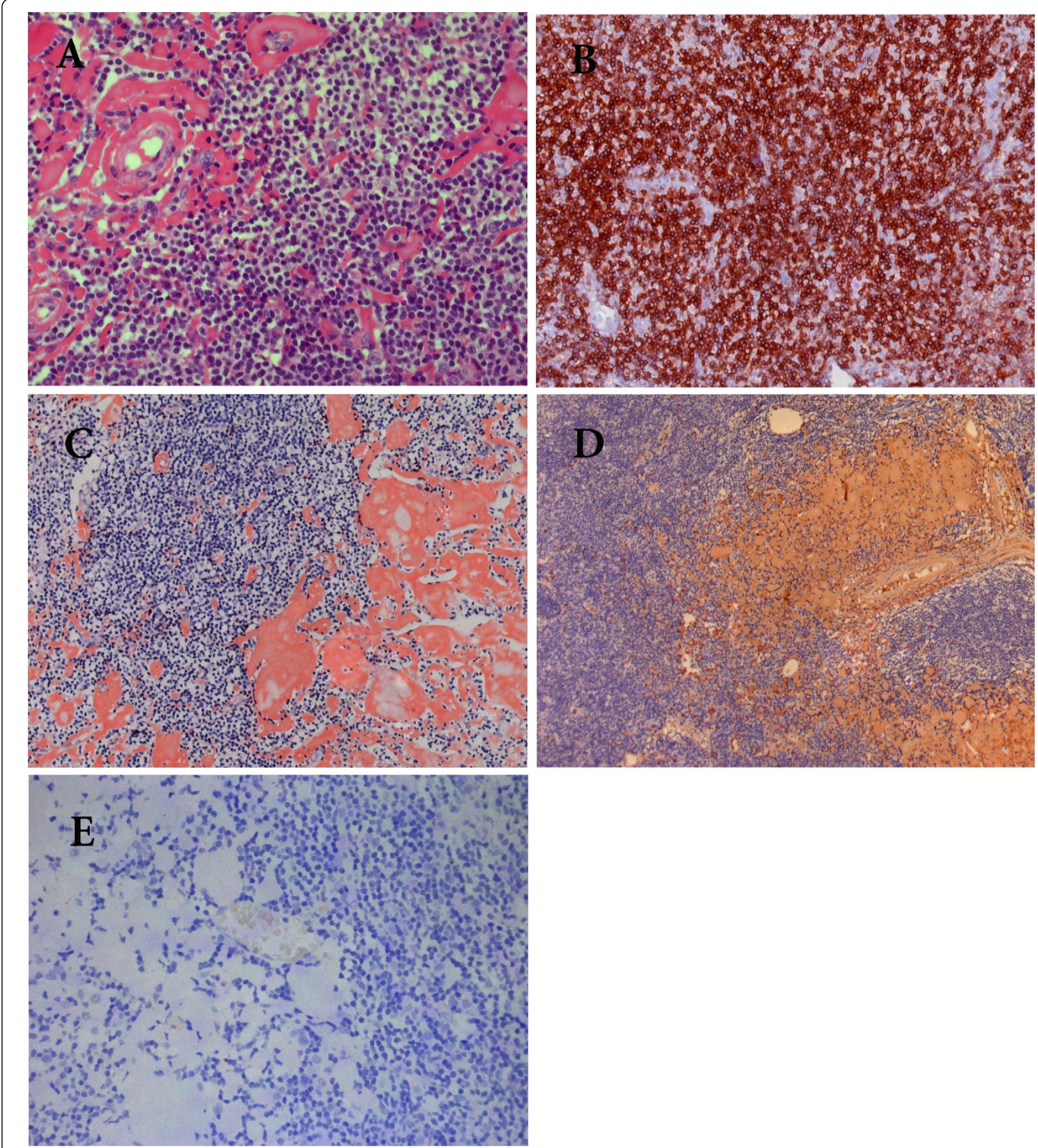

Figure 3 Photomicrographs of histological changes of the affected lymph node. (A). Lymph node involved showing diffuse small lymphocyte-like cells and patches of homogenous materials in the dark background of proliferating cells. (HE staining $\times 400)$. (B) The proliferating cells are CD5 positive by immunohistochemistry (×200). (C). The deposit was strongly Congon-Red positive. (×200). (D). Strong positivity of $\kappa$ light chain demonstrated by immunohistochemistry $(\times 100)$. (E). The deposit was completely negative for $\lambda$ light chain. $(\times 200)$.

indicates the secondary local inflammatory response, while the monotonous appearance of the cells usually suggests tumor infiltration. But when it comes to a biopsy specimen, it is difficult to distinguish both situations due to the local distribution of the infiltration. In this regard, further immunohistochemical examinations should be applied. In general, leukemic infiltration in the kidney should be considered when a patient with CLL presents with renal impairment. This kind of patients usually responds well to chemotherapy as seen in our case $[8,14,15]$. 

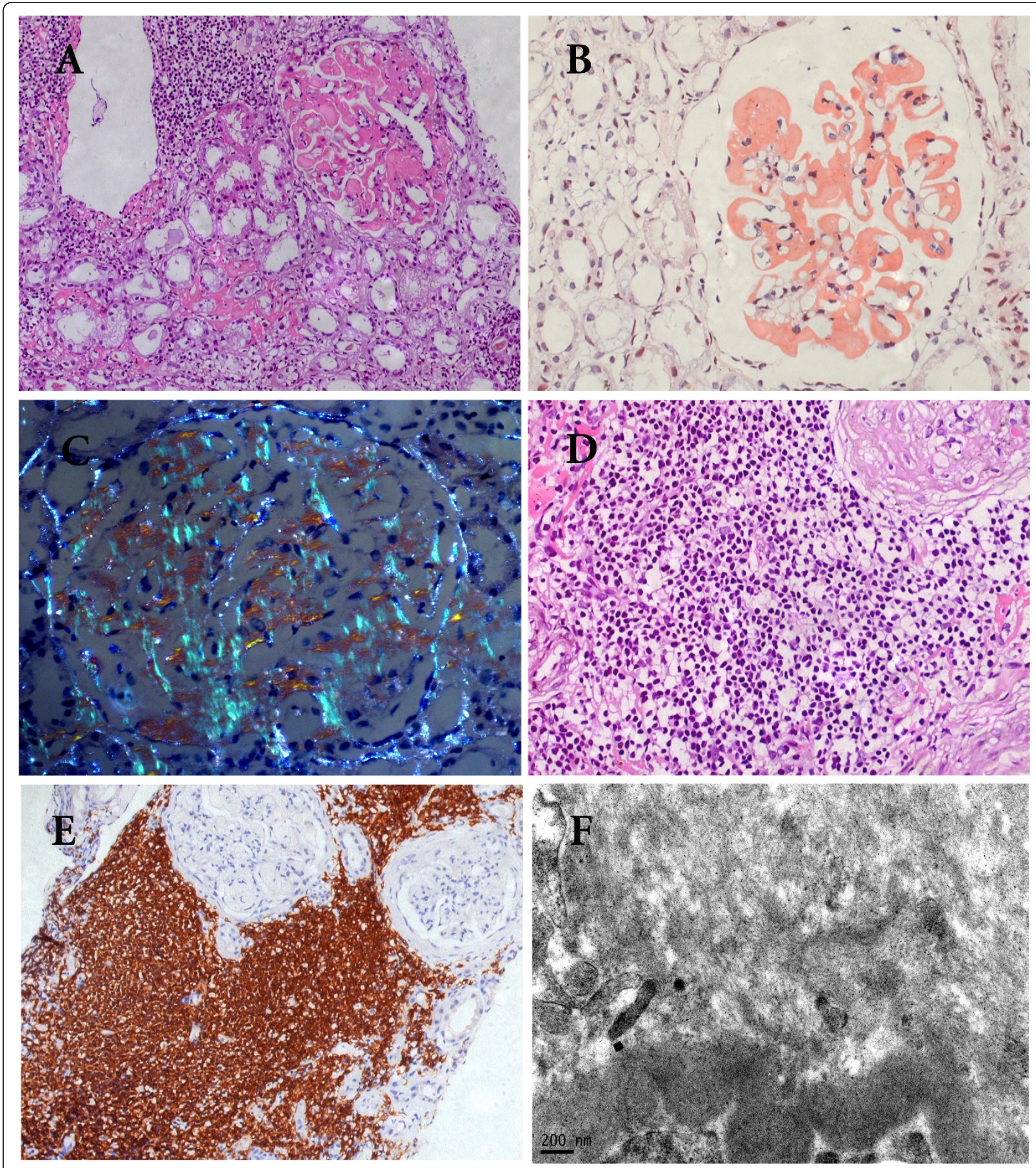

Figure 4 Photomicrographs of histological changes of the renal biopsy. (A) Renal biopsy illustrated small lymphocyte-like cell infiltrate in the interstitial tissue. The glomeruli showed amorphous eosinophilic material in the meangium and extending to the peripheral capillary walls leading the obliteration of segmental capillary loop. Foci of deposition were found in the interstitial and peritubular space. (HE staining $\times 200)$. (B). Salmon pink staining of the glomeruli with Congo red staining. $(\times 400)$. (C). Apple green birefringence was detected under polarized light ( $\times 400)$. (D) Uniform small lymphoid cell infiltrate in a nodular pattern around a sclerotic glomerulus. (HE staining $\times 200$ ). (E) The infiltrating cells in the interstitium were CD20 positive by immunohistochemistry (×200). (F) Non-branched and randomly arranged fine fibrils in a diameter of $10 \mathrm{~nm}$ were found in the glomerular mesangial area $(\times 37000)$. 
AL amyloidosis can be complicated with any clonal B cell dyscrasia, especially plasma cell dyscrasia. The misfolded monoclonal free light chains deposited in the extracellular space in a fibrillar form which are very hard to be absorbed. Accumulation of these fibrils in the kidney causes progressive renal impairment with proteinuria, even renal failure. It is well known that most amyloid depositions associated with plasma disorders are lambda-light chains [16]. On the contrary, in AL amyloid caused by CLL, the monoclonal light chains detected are predominantly kappa type as in our case $[3,5]$. Though AL amyloidosis caused by plasma cell dyscrasia often has a poor prognosis with a median survival of 35.2 months from diagnosis due to the poor response to chemotherapy [17], CLL-associated AL amyloidosis were reported to be significantly alleviated and obtained a prolonged survival of more than 7 years [2]. As with our patient, his proteinuria decreased very slowly and did not resolve until one year after he obtained hematologic remission. This is believed to be associated with the reduced production of amyloidogenic light chains so that the clearance of existing deposits exceeds the rate of deposition. Those deposited amyloids were gradually mobilized and cleared by the body.

Another interesting finding is that the serum concentration of C3 in our patient changed significantly after chemotherapy. It was in the lowest level when the patient was in acute phase and the serum IgM was high. With the decrease of serum IgM after treatment, it recovered to the normal level, indicating that impaired complement system might be involved in the pathogenesis of CLL and its complications [18].

\section{Conclusion}

We herein first reported a rare case of nephrotic syndrome combined with acute renal failure caused by CLL. From our patient and few cases reported in the literature, we suggest that AL amyloidosis should be considered in CLL patients presenting with proteinuria or nephrotic syndrome. AL amyloidosis associated with CLL may have a more favorable prognosis than those caused by multiple myeloma due to a better response to chemotherapy. Further investigations are needed to better clarify the clinical outcomes and prognosis of this unusual complication of CLL and to better understand the pathological and molecular mechanisms of CLLinduced nephrotic syndrome.

\section{Consent}

A written informed consent was obtained from the patient for publication of this case report and any accompanying images. A copy of the written consent is available for review by the Editor-in-Chief of this journal.

\section{Author details}

'Department of Nephrology, the Affiliated Shunde First People's Hospital of Southern Medical University, Penglai Road, Daliang District, Foshan 528300, China. ${ }^{2}$ Department of Pathology, the First Affiliated Hospital of Sun Yat-sen University, $58^{\#}$ Zhongshan Road II, Guangzhou 510080, China. ${ }^{3}$ Department of Pharmaceutical Sciences, College of Pharmacy, University of South Florida, Tampa, Florida 33612, USA.

\section{Authors' contributions}

XRD has drafted the manuscript. HTH and YLJ have made contributions to acquisition of clinical data. YDL and KFK have carried out the tissue staining, immunoassays and electronic microscopic examination. SFZ has revised the manuscript carefully. WFC has made analysis of the histological features and the clinical-pathological relations. All authors read and approved the final manuscript.

\section{Competing interests}

The authors declare that they have no competing interests.

Received: 29 May 2011 Accepted: 13 October 2011

Published: 13 October 2011

\section{References}

1. Gertz MA, Lacy MQ, Dispenzieri A, Hayman SR: Amyloidosis. Best Pract Res Clin Haematol 2005, 18:709-927.

2. Sanchorawala V, Blanchard E, Seldin DC, O'Hara C, Skinner M, Wright DG: AL amyloidosis associated with B-cell lymphoproliferative disorders: frequency and treatment outcomes. Am J Hematol 2006, 81:692-695.

3. Ikee R, Kobayashi S, Hemmi N, Suzuki S, Miura S: Amyloidosis associated with chronic lymphocytic leukemia. Amyloid 2005, 12:131-134.

4. Muftuoglu AU, Erbengi T, Harmanci M, Karayel T, Gursoy E, Tahsinoglu M: Renal amyloidosis: immunofluorescence and electron microscopy studies. Isr J Med Sci 1977, 13:1102-1108.

5. Rochman J, Lichtig C, Osterweill D, Tatarsky I, Eidelman S: Adult Fanconi's syndrome with renal tubular acidosis in association with renal amyloidosis: occurrence in a patient with chronic lymphocytic leukemia. Arch Intern Med 1980, 140:1361-1363.

6. Barcos M, Lane W, Gomez GA, Han T, Freeman A, Preisler H, Henderson E: An autopsy study of 1206 acute and chronic leukemias (1958 to 1982). Cancer 1987, 60:827-837.

7. Kowalewska J, Nicosia RF, Smith KD, Kats A, Alpers CE: Patterns of glomerular injury in kidneys infiltrated by lymphoplasmacytic neoplasms. Hum Pathol 2011, 42:896-903.

8. Hewamana S, Pepper C, Jenkins C, Rowntree C: Acute renal failure as the presenting feature of leukaemic infiltration in chronic lymphocytic leukaemia. Clin Exp Nephrol 2009, 13:179-181.

9. Lentaigne C, Craig C, Cwynarski K, Prentice A, McNamara C: Chronic lymphocytic leukemia can cause acute renal failure even in early stage patients. Leuk Lymphoma 2010, 51:333-334.

10. Erten N, Saka B, Caliskan YK, Besisik S, Karan MA, Tascioglu C: Acute renal failure due to leukaemic infiltration in chronic lymphocytic leukaemia: case report. Int J Clin Pract 2005, 147(Suppl 1):53-55.

11. Hill PA, Firkin F, Dwyer KM, Lee P, Murphy BF: Membranoproliferative glomerulonephritis in association with chronic lymphocytic leukaemia: a report of three cases. Pathology 2002, 34:138-143.

12. Yahata N, Kawanishi Y, Okabe S, Kimura Y, Okada T, Otani M, Shimizu T, Nakao T, Ohyashiki K: Membranous glomerulonephritis with nephrotic syndrome associated with chronic lymphocytic leukemia. Am J Nephrol 2000, 20:402-407.

13. Alzamora MG, Schmidli M, Hess U, Cathomas R, von Moos R: Minimal change glomerulonephritis in chronic lymphocytic leukemia: pathophysiological and therapeutic aspects. Onkologie 2006, 29:153-156.

14. Da'As N, Polliack A, Cohen Y, Amir G, Darmon D, Kleinman Y, Goldfarb AW, Ben-Yehuda D: Kidney involvement and renal manifestations in nonHodgkin's lymphoma and lymphocytic leukemia: a retrospective study in 700 patients. Eur J Haematol 2001, 67:158-164.

15. Phillips JK, Bass PS, Majumdar G, Davies DR, Jones NF, Pearson TC: Renal failure caused by leukaemic infiltration in chronic lymphocytic leukaemia. J Clin Pathol 1993, 46:1131-1133. 
16. Hopfer H, Wiech T, Mihatsch MJ: Renal amyloidosis revisited: amyloid distribution, dynamics and biochemical type. Nephrol Dial Transplant 2011, 26:2877-2884.

17. Pinney JH, Lachmann HJ, Bansi L, Wechalekar AD, Gilbertson JA, Rowczenio D, Sattianayagam PT, Gibbs SD, Orlandi E, Wassef NL, et al: Outcome in renal Al amyloidosis after chemotherapy. J Clin Oncol 2011, 29:674-681.

18. Schlesinger M, Broman I, Lugassy G: The complement system is defective in chronic lymphatic leukemia patients and in their healthy relatives. Leukemia 1996, 10:1509-1513.

doi:10.1186/1746-1596-6-99

Cite this article as: Dou et al: Concurrent nephrotic syndrome and acute renal failure caused by chronic lymphocytic leukemia (CLL): a case report and literature review. Diagnostic Pathology 2011 6:99.

Submit your next manuscript to BioMed Central and take full advantage of:

- Convenient online submission

- Thorough peer review

- No space constraints or color figure charges

- Immediate publication on acceptance

- Inclusion in PubMed, CAS, Scopus and Google Scholar

- Research which is freely available for redistribution

Submit your manuscript at www.biomedcentral.com/submit
C) Biomed Central 